\title{
Benefits of breastfeeding and women's health
}

\author{
Marina F. Rea*
}

\begin{abstract}
Objective: To review breastfeeding benefits for the women's health.

Sources of data: Lilacs, MEDLINE, SciELO, BIREME, Cochrane Library and Google were searched for the keywords: breastfeeding and breast cancer, ovarian cancer, osteoporosis, rheumatoid arthritis, lactation amenorrhea, post nata period, and women's health. Single articles published between 1990 and 2004 were considered, as well as remarkable ones prior to this period.

Summary of the findings: There are a few articles published on the topic, even though, the existing literature reveals that there is a positive relationship between breastfeeding and decreased risk of breast cancer, cancer of the ovarian epithelium, and osteoporosis leading to hip fracture. Some studies suggest the effect of breastfeeding on the decreasing risk of rheumatoid arthritis, others mention the relation between breastfeeding and faster loss of weight gained during the gestational period. Several studies show how breastfeeding interferes on the onset of postnatal menstruation and consequent birth spacing.

Conclusions: breastfeeding provides important benefits for the women's health, such as reduced risk of breast and ovarian cancer, decreased risks of hip fractures and contribution to the increase of birth spacing.

J Pediatr (Rio J). 2004;80(5 Suppl):S142-S146: Breastfeeding, breast cancer, ovarian cancer, lactational amenorrhea, arthritis rheumatoid, women's health.
\end{abstract}

\section{Introduction}

The number of scientific evidences on the fact that breastfeeding is the best source of nutrition for infants has been increasing, and health authorities have recommend breastfeeding implementation through policies and measures that prevent early weaning. The objective of this study is to review scientific evidences on the benefits of breastfeeding for women's health. Although sometimes during their clinical practice pediatricians do not evaluate or provide guidance to the mothers who attend their offices, it is very useful to pediatricians to know the benefits of breastfeeding for mothers' health. This knowledge might be employed in several situations.

Literature does not provide a large amount of articles about the benefits of breastfeeding for women's health. However, a positive relationship between breastfeeding and reduced incidence of diseases such as breast cancer, $1-13$ certain types of ovarian cancer, ${ }^{10,14-17}$ and bone fractures,

* Ph.D. Instituto de Saúde, Coordenação dos Institutos de Pesquisa (CIP), SES - São Paulo, SP, Brazil.

Suggested citation: Rea MF. Benefits of breastfeeding and women's health. J Pediatr (Rio J). 2004;80(5 Suppl):S142-S146. mainly hip fractures caused by osteoporosis. ${ }^{10,18-22}$ There are also evidences that breastfeeding reduces the risk of death from rheumatoid arthritis. ${ }^{23-27}$ Many studies have presented the relationship between breastfeeding and postnatal amenorrhea, and the occurrence of a consequent longer intergestational period. ${ }^{10,28-41}$ Other benefits for lactating women are the faster loss of weight gained during the pregnancy, ${ }^{38-40,42-45}$ and the reduced postnatal uterine bleeding, which leads to less anemia ${ }^{10}$ due to the faster uterus involution caused by the greater oxytocin release. 46

If compared to the advance of the knowledge about the role played by breastfeeding and the human milk in the infants' health, the knowledge about the benefits of breastfeeding for women is scarce, and, therefore, this topic must be further investigated in the next decades.

\section{Breast cancer}

There are many studies on the relationship between breast cancer and breastfeeding. During a certain period of time, it was controversial whether the protection of breastfeeding against breast cancer lasted during the whole reproductive period or if it was related to menopause. ${ }^{10} \mathrm{~A}$ 
study carried out in Iceland, involving 993 cases of breast cancer and 9,729 controls, has revealed a dose-response relationship between the number of months of breastfeeding and less probability of breast cancer in the younger age group ( $>40$ years), however, this was not the case for the other groups. ${ }^{2}$ On the other hand, a study performed in China has showed that this relationship does exist but only in older postmenopausal women. ${ }^{5}$

A review of the literature between 1966 and 1998 shows that some authors suggest the occurrence of breastfeeding protection against breast cancer in American and European women before menopause; ${ }^{1,4}$ other researchers have confirmed such findings in other female populations. ${ }^{11-13}$ Romieu et al. have showed, in a case control study in Mexico, that such a relationship exists in pre-menopausal as well as postmenopausal women. ${ }^{6}$ Olaya-Contreras et al. have found important evidences of breastfeeding protection against breast cancer in women from Colombia. ${ }^{7}$ The same finding has not been obtained in the study by Tessaro et al. involving women from the South region of Brazil, 8 even though such a relationship had been shown before in this country by Hardy et al. ${ }^{9}$

A review of 47 studies carried out in 30 countries, involving about 50,000 women with breast cancer, and 97,000 controls, suggests that breastfeeding may be responsible for $2 / 3$ of the estimate reduction of breast cancer. ${ }^{3}$ The longer the duration of breastfeeding the greater the protection: the relative risk of cancer decreased $4.3 \%$ every 12 months of breastfeeding duration, regardless women's nationalities (developed countries versus developing countries), age, race, presence or absence of menopause and number of children. It was estimated that the incidence of breast cancer in developed countries could be reduce to less than half (from 6.3 to $2.7 \%$ ) if breastfeeding duration was longer.

\section{Ovarian cancer}

Ovarian cancer has one of the highest rates of mortality if compared to other types of cancer. In the United States it causes more deaths than cervical and endometrial cancer. The survival rate after the treatment still remains low, which reveals the necessity of greater investments in its prevention. Cancer of the ovarian epithelium is the most common type of ovarian cancer (nine out of 10 cases), and its occurrence rate is the same in both ovaries, but it usually does not affect young women and girls. Studies have shown that in a decreasing order of significance the protective factors associated with ovarian cancer are the following: use of oral contraceptive; pregnancy and breastfeeding; ligature of the Fallopian tubes and hysterectomy; prophylactic oophorectomy; and no exposure to agents associated with the disease, such as talcum powder, hormonal therapy and drugs used to treat infertility. ${ }^{15}$ Even though the etiopathogeny of this disease is not completely clear, one of the reasonable hypothesis is that cancer would occur in the ovarian epithelium due to uninterrupted traumas of ovulations and cell proliferations, which would produce cysts where the malign cells might reproduce more easily. This theory might explain the reason why ovulation intervals and the consequent "break" for the ovary, such as the interval that takes place while women are breastfeeding, would be associated with a lower risk of cancer.

Although there are few studies relating breastfeeding and ovarian cancer, it is possible to consider that the risk of the disease is lower in women who breastfeed. 10,14 Tung et al., in a case control study performed in California, have showed that a lower risk of ovarian cancer among women who breastfed occurred for all types of tumors of the ovarian epithelium, except for invasive mucinous tumors. ${ }^{16}$ These authors have also found an inverse and significant relationship: the longer the breastfeeding duration, the lower the risk of nonmucinous ovarian cancer - clear cells and endometrioid cancers. Riman et al., while studying 655 Swedish women from 50 to 74 years old and 3,899 controls, have also demonstrated breastfeeding protection against ovarian cancer, but only regarding clear cell tumors. These authors suggested the hypothesis that there is a etiopathogeny of ovarian cancer related to retrograde blood flow and other substances (such as talcum powder, for example) through the Fallopian tubes. ${ }^{17}$

\section{Bone fractures due to osteoporosis}

During lactation women produce between 600 and 1,000 $\mathrm{ml}$ of milk a day, with a mean daily loss of calcium of $200 \mathrm{mg}$, which could lead to bone fractures due to the loss of this mineral, especially if they exclusively breastfeed for 6 months (as recommended). Therefore, it would be reasonable to suppose that breastfeeding increases the risk of bone fractures, since calcium losses and hormonal alterations that take place during pregnancy and lactation can be responsible for changes in the bones, making them more prone to fractures. However, such a loss is naturally recovered during weaning period and when menstruation is resumed. Actually, in a study carried out in Minnesota, United States, bone mass showed to have a greater mineral density among women who breastfed for longer than 8 months. ${ }^{19}$ Another study has shown that breastfeeding protects against the risk of hip bone fracture, ${ }^{20}$ even though this conclusion has lost credibility due to the fact that parity was not taken into consideration, since it is well-known as a factor associated with fractures. ${ }^{21}$ Alderman et al. have also demonstrated breastfeeding protection against hip and arm fractures caused by osteoporosis. ${ }^{22}$ However, Michaelsson et al. have not found any relationships between breastfeeding and the risk of hip fracture in Swedish women taking parity into consideration. ${ }^{21}$ Nevertheless, other authors suggest that breastfeeding, considering or not parity, can reduce the risk of bone fractures caused by osteoporosis. ${ }^{18}$

\section{Rheumatoid arthritis}

The breastfeeding protection factor against rheumatoid arthritis still remains unproven. The etiology of the disease is not clear yet, but studies performed with twins have shown that about $60 \%$ of the disease probability might be caused by genetic heritage, although is not completely 
clear whether the family genetic heritage would aggravate the disease or not. ${ }^{27}$ The environmental factors would be responsible for the remaining cases of the disease. Therefore, according to this, there is not a unique factor responsible for causing rheumatoid arthritis. There are evidences that hormonal alterations in the perinatal period could be associated with the disease, since it does not occur during pregnancy, being more common during the postnatal period. ${ }^{26}$ Therefore, the prevalent factors during the reproductive cycle needs to be further investigated.

In a study performed by Brun et al., more than 60,000 Norwegian women were followed for 29 years, and the characteristics of their reproductive periods were studied. Three-hundred and fifty-five cases of rheumatoid arthritis were found in their death certificates. The total duration of lactation was associated to a lower mortality rate for rheumatoid arthritis. The authors stated that since this is the first research that shows this association, it would be necessary to repeat the study in other populations. ${ }^{23}$ With the purpose of studying the relationship between rheumatoid arthritis and perinatal factors, a study carried out in Sweden, involving 77 women with rheumatoid arthritis and 308 controls, revealed an inverse relationship between breastfeeding initiation at the hospital and mortality caused by rheumatoid arthritis. ${ }^{24}$ In another case control study with 88 English women who developed rheumatoid arthritis after their first child was born, the incidence of the disease was five times more frequent among those who breastfed. 25

\section{Weight loss after the delivery}

Adult women who practice moderate physical activities need 2,000 to 2,200 calories and $40-45 \mathrm{~g}$ of protein a day to keep their weight and metabolism. While they are breastfeeding, an additional amount of 500-640 calories and about $16 \mathrm{~g}$ of protein are necessary. Since there is an accumulation of about 100-150 calories a day during pregnancy, women are often overweight at the end of the pregnancy. Therefore, in general, women loss the weight gained during pregnancy after a variable period of time. After delivery, when the woman's body is prepared for lactation, that is, for producing maternal milk, she might not eat the amount of calories necessary to produce the amount of milk her baby takes. If she is breastfeeding, her body will use that amount of accumulated calories to produce milk. ${ }^{42}$ If the infant is exclusively breastfed, that is, if all the calories ingested by the baby come from his/ her mother, the amount of calories taken from the mother will be greater. ${ }^{43}$ Therefore, if the mother stops breastfeeding early, she will keep the calories that would otherwise be used to produce milk. The puerpera will keep the weight she gained during pregnancy and it will take longer to lose weight.

In poor regions, where a pregnancy often is followed by another pregnancy, the accumulation of weight due to those multiple pregnancies in puerperas can contribute to obesity of adult women. According to the recommendation of the World Health Organization, exclusive breastfeeding for 6 months contributes to a faster loss of weight. ${ }^{38-40}$ In a longitudinal study involving 312 women from the South of Brazil, Gigante et al. have showed that women who breastfed from 6 to 12 months presented the lowest indexes of body mass and skin fold measures. In addition, those who use exclusive or predominant breastfeeding were more prone to be thinner than those who partially breastfed or did not breastfeed. 43

Motil et al., in a small sample from the United States, while following lactating, no lactating women and women who had no children, have found out that, even though lactating women presented more body fat up to 18 weeks after the delivery, they lost weight in a slow and gradual manner up to 12 months. After 1 year, the skin folds of the three groups presented no significant difference. ${ }^{44}$

It is important to highlight that it has been already demonstrated that the weight loss of lactating women who exclusively breastfeed, which might reach $500 \mathrm{~g}$ a week between the fourth and the 14th week, does not interfere with the infants' growth. ${ }^{45}$

\section{Lactational amenorrhea}

Lactational amenorrhea is the period of physiological amenorrhea that follows the delivery in lactating women. Milk production ceases during pregnancy because of the increase in the progesterone blood level, with the consequent filling of the breasts with colostrum, and it resumes due to the placental delivery. Regardless the infant's sucking and the removal of the milk, there is an important increase in the volume of the breasts in the postnatal period. If there is suction, the nervous terminations of the nipple and the areola are stimulated. These stimuli reach the hypothalamus, which, on its turn, induces prolactin release through the anterior hypophysis and oxytocin release through the posterior hypophysis. This way, lactation is maintained.

Considering the presence of other hormones, such as cortisol, insulin, thyroid and parathyroid hormones, and growth hormones, which are also involved in lactation, prolactin is the main hormone, and it also interferes with the ovaries by inhibiting the ovulation and maintaining amenorrhea. Apparently, the stimuli of suction and the increase of prolactin lead to the inhibition of the gonadotrophic hormone and cause the interruption of the ovulation process during lactation. However, this mechanism has not been completely explained yet. In the cycle of a no lactating woman, the hypothalamus releases gonadotrophic hormone through pulses, which stimulates the release of the luteinizing hormone (LH) from the anterior pituitary; LH leads to an increase in the volume and number of the ovarian follicles, the production of estrogen and the consequent ovulation.

In population that keep long periods of breastfeeding on demand, the intervals between pregnancies are long and lactational amenorrhea is the natural "contraceptive method". ${ }^{10,28-30}$ Among the several aspects that could be involved in the maintenance of infertility in the postnatal period, the infant's sucking seems to be the most important 
one. The great difficulty found by the researchers has been establishing the adequate quantification of suction - frequency, strength, volume of sucked milk (these aspects would measure the efficacy of lactation as a contraceptive). Several methods have been used - breast size, breast weight before and after breastfeeding, use of isotopes -, but these methods have not been successful. A study performed in Philippines and in the United States used a method that has proven to be more trustful: the number of feedings was measured among the total number of food intakes of the infants, that is, the relative frequency of feedings; women whose ovulation took place before the sixth month of the infant's life breastfed significantly less times than the other women. 32,33

Among Scottish women, it has been observed that ovulation does not occur while the infant is being breastfed for at least six times for a total of 65 minutes distributed in 24 hours. ${ }^{34}$ However, other studies have not confirmed this finding, and they have suggested that there is not a minimal number of feedings that guarantees the ovulation interval. ${ }^{35}$ Once any other kind of liquid is introduced in the infant's diet, the infant tends to suck less because his hunger and thirst are partially appeased by these liquids. Therefore, it is possible to suppose that the exclusive breastfeeding contributes to delay the return of fertility. This was demonstrated in 1987, when Huffman et al. published a study involving women from Bangladesh, and they concluded that the practice of exclusive breastfeeding for 7 months led to a longer mean duration of lactational amenorrhea if compared to mixed breastfeeding. ${ }^{41}$ Similar results were obtained with women from Honduras. ${ }^{37} \mathrm{~A}$ study performed in 1992 by Benitez et al. ${ }^{31}$ has showed that complementary food might interfere with the duration of the lactational amenorrhea, even if the number and the duration of the feedings are maintained after the introduction of complementary food.

If a woman wants to use breastfeeding as a contraceptive method, she must: (1) do this in the first 6 months after the delivery; (2) not have had a menstrual period; and (3) exclusively or almost exclusively breastfeed. These recommendations are still based in the so-called Bellagio Consensus, released in 1988, which was based on the review of all the studies on this topic published up to that time. According to the Consensus, "breastfeeding provides more than $98 \%$ of the protection against pregnancy in the first 6 months after the delivery if the woman did not menstruate after the 56th day and if she exclusively or almost exclusively breastfeeds". ${ }^{1}$

In a review on lactational amenorrhea as a contraceptive method, the so-called LAM (Lactational Amenorrhoea Method), 36454 studies were identified as potentially relevant. Among these studies, 13 have investigated the risk of pregnancy while using LAM by applying criteria and parameters that could be compared to other studies. The results have showed that there was no difference between the pregnancy rates of women who used LAM (aware of the method) if compared to those with amenorrhea and who were breastfeeding but did not use any contraceptive method. However, there are pitfalls in this study, mainly regarding the heterogeneity between the groups of populations with different breastfeeding habits. It has not been proven if LAM delays the return of the menstruation. There are also suggestions of the use of better term definitions, clear indication of cases and controls, age, cultural heritage, breastfeeding patterns, amenorrhea and parity in new studies.

\section{Final considerations}

In a broad and recent literature review, evidences demonstrated important benefits of breastfeeding for women's health, with the confirmation of lower risk of breast cancer. The lower risk occurs either before or after menopause. There are also evidences of breastfeeding protection against some types of cancer of the ovarian epithelium.

The contribution of lactation is evident and well documented, especially regarding exclusive breastfeeding, in terms of longer intervals between pregnancies; this fact led to a worldwide recommendation of the use of LAM, based on the Bellagio Consensus, which lacks divulgation. Further studies, with better methodological design, are necessary in order to better understand the relationship between lactation, mineral bone depletion, osteoporosis and pathological fracture. It would also be opportune to repeat the studies involving different populations in order to further investigate the findings related to the evidences of a lower rate of rheumatoid arthritis among women who breastfed.

Information about the faster weight loss during exclusive breastfeeding, which is based on scientific evidences, might be useful to women.

\section{Acknowledgements}

The authors would like to thank the technical research assistants Lucélia Fernandes and Rita Ciconi (CNPq fellowship) for their support regarding the search for bibliographic references.

\section{References}

1. Newcomb PA, Storer BE, Longnecker MP, Mittendorf R, Greenberg ER, Clapp RW, et al. Lactation and a reduced risk of premenopausal breast cancer. N Engl J Med. 1994;330:81-7.

2. Tryggvadottir L, Tulinius H, Eyfjord JE, Sigurvinsson T. Breastfeeding and reduced risk of breast cancer in an Iceland cohort study. Am J Epidemiol. 2001;154:37-42.

3. Collaborative Group on Hormonal Factors in Breast Cancer. Breast cancer and breastfeeding: collaborative reanalysis of individual data from 47 epidemiological studies in 30 countries, including 50302 women with breast cancer and 96973 women without the disease. Lancet. 2002;360:187-95.

4. Lipworth L, Bailey R, Trichopoulos D. History of breastfeeding in relation to breast cancer risk: a review of the epidemiologic literature. J Natl Cancer Inst. 2000;92:302-12.

5. Gao Y-T, Shu X-O, Daí Q, Potter JD, Brinton LA, Wen W, Sellers $T A$, et al. Association of menstrual and reproductive factors with breast cancer risk: results from the Shanghai Breast Cancer Study. Int J Cancer. 2000;87:295-300. 
6. Romieu I, Hernandez-Avila M, Lazcano E, Lopez R, RomeroJaime R. Breast cancer and lactation history in Mexican women. Am J Epidemiol. 1996;143:543-52.

7. Olaya-Contreras $P$, Buerkens $P$, Lazcano-Ponce $E$, VillamiRodriguez J, Posso-Valencia HJ. Factores de riesgo reproductivo asociados al cancer mamario, en mujeres colombianas. Rev Saúde Publ. 1999;33:4-45.

8. Tessaro S, Béria JU, Tomasi E, Victora CG. Amamentação e câncer de mama: estudo de caso-controle no Sul do Brasil. Cad Saúde Publ. 2003;19:1593-601.

9. Hardy E, Pinotti JA, Faundes AE, Osis MJD. Variáveis reprodutivas e risco para câncer de mama: estudo caso-controle desenvolvido no Brasil. Bol Oficina Sanit Panam. 1993;115:93-102.

10. Labbok MH. Effects of breastfeeding on the mother. Pediatr Clin North Am. 2001;48:143-58.

11. Brinton L, Potischman N, Swanson C, Schoenberg JB, Coates RJ, Gammon MD, et al. Breastfeeding and breast cancer risk. Cancer Causes Control. 1995;6:199-208.

12. Chilvers $C$. Breastfeeding and risk of breast cancer in young women. BMJ. 1993;307:17-20.

13. Enger S, Ross R, Henderson B, Bernstein L. Breastfeeding history pregnancy experience and risk of breast cancer. $\mathrm{Br}$ J Cancer. 1997;76:118-23.

14. Rosenblatt KA, Thomas DB. WHO Collaborative Study of Neoplasia and Steroid Contraceptives. Int J Epidemiol. 1993;22:192-7.

15. National Cancer Institute [homepage on the Internet]. University of Bonn, Medical Center [updated 2004 Sep 3; cited 2004 Sep 21]. Prevention of ovarian cancer; [about 10 screens]. Available from: http://www.meb.uni-bonn.de/cancer.gov/ CDR0000062771.html

16. Tung $\mathrm{KH}$, Goodman MT, Wu Anna $\mathrm{H}$, McDuffie $\mathrm{K}$, Wilkens LR, Kolonel LN, et al. Reproductive factors and epithelial ovarian cancer risk by histologic type: a multiethnic case-control study. Am J Epidemiol. 2003;158:629-38.

17. Riman T, Dickman PW, Nilsson S, Correia N, Nordlinder $H$, Magnusson CM, et al. Risk factor for invasive epithelial ovarian cancer: results from a Swedish case-control study. Am J Epidemiol. 2002;156:363-73.

18. Cumming RG, Klineberg RJ. Breastfeeding and other reproductive factors and the risks of hip fractures in elderly woman. Int J Epidemiol. 1993;22:684-91.

19. Melton LJ, Bryant SC, Wahner HW, O'Fallon WM, Malkasian GD, Judd $\mathrm{HL}$, Riggs BL. Influence of breastfeeding and other reproductive factors on bone mass later in life. Osteoporos Int. $1993 ; 3: 76-83$.

20. Kreiger N, Kelsey JL, Holford TR, O'Connor T. An epidemiological study on hip fracture in postmenopausal women. Am J Epidemiol. 1982;116:141-8.

21. Michaelsson K, Baron JA, Farahmand BY, Ljunghall S. Influence of parity and lactation on hip fracture risk. Am J Epidemiol. 2001; 153:1166-72.

22. Alderman B, Weiss N, Daling J, Ure CL, Ballard JH. Reproductive history and postmenopausal risk of hip and forearm fracture. Am J Epidemiol. 1986;124:262-7.

23. Brun JG, Nilssen S, Kvale G. Breastfeeding, other reproductive factors and rheumatoid arthritis: a prospective study. $\mathrm{Br}$ J Rheumatol. 1995;34:542-6.

24. Jakobsson LTH, Jakobsson ME, Askling J, Knowler WC. Perinatal characteristics and risks of rheumatoid arthritis. BMJ. 2003;326:1068-9.

25. Brennan P, Silman A. Breastfeeding and the onset of rheumatoid arthritis. Arthritis Rheumat. 1994;37:808-13.

26. Silman AJ, Kay A, Brennan P. Timing of pregnancy in relation to the onset of rheumatoid arthritis. Arthritis Rheum. 1992;35; 152-5.

27. MacGregor AJ, Snieder H, Rigby AS, Koskenvuo M, Kaprio J, Aho $\mathrm{K}$, et al. Characterizing the quantitative genetic contribution to rheumatoid arthritis using data from twins. Arthritis Rheum. 2000;43:30-7.

28. Kennedy KI, Visness CM. Contraceptive efficacy of lactational amenorrhoea. Lancet. 1992;339:227-30.
29. Gray RH, Campbell OM, Apelo R, Eslami SS, Zacur H, Ramos RM, et al. Risk of ovulation during lactation. Lancet. 1990;335:25-9.

30. Labbok MH, Colie C. Puerperium and breastfeeding. Curr Opin Obstetr Gynecol. 1992;4:818-25.

31. Benitez I, de la Cruz J, Suplido A, Oblepias V, Kennedy K, Visness C. Extending lactational amenorrhoea in Manila: a successful breastfeeding education program. J Biosoc Sci 1992;24:211-31.

32. Gray RH, Campbell R, Apelo S, Eslami SS. Risk of ovulation during lactation. Lancet. 1990;335:25-9.

33. Eslami SS, Gray RH, Apelo S, Ramos RM. The reliability of menses to indicate the return of ovulation in breastfeeding women in Manila, The Philippines. Stud Fam Plann. 1990;21: 243-50.

34. McNeilly AS, Glasier AF, Howie PW, Houston MJ, Cook A, Boyle H. Fertility after childbirth: pregnancy associated with breastfeeding. Clin Endocrinol. 1983;18:167-73.

35. Shaaban MM, Kennedy KI, Gayed GII, Ghaneimah AS, AbdelAleem AM. The recovery of fertility during breastfeeding in Assiut, Egypt. J Biossoc Sci. 1990;22:19-32.

36. Van der Wijden C, Kleijnen J, Van der Berk T. Lactational amenorrhoea for family planning (Cochrane Review). In: The Cochrane Library, Issue 1, 2004. Oxford: Update Software.

37. Dewey KG, Cohen RJ, Rivera LL, Canahuati J, Brown KH. Effects of age at introduction of complementary foods to breast-fed infants on duration of lactational amenorrhea in Honduran women. Am J Clin Nutr. 1997;65:1403-9.

38. Cohen RJ, Brown KH, Canahuati J, Rivera LL, Dewey KG. Effects of age of introduction of complementary foods on infant breast milk intake, total energy intake, and growth: a randomised intervention study in Honduras. Lancet. 1994;344:288-93.

39. Cohen RJ, Brown KH, Canahuati J, Rivera LL, Dewey KG. Determinants of growth from birth to 12 months among breastfed Honduran infants in relation to age of introduction of complementary foods. Pediatrics. 1995;96:504-10.

40. Dewey KG, Cohen RJ, Brown KH, Rivera LL. Effects of exclusive breastfeeding for four versus six months on maternal nutritional status and infant motor development: results of two randomised trials in Honduras. J Nutr. 2001;131:262-7.

41. Huffman SL, Ford K, Allen HA, Streble P. Nutrition and fertility in Bangladesh: breastfeeding and post partum amenorrhea. Popul Stud. 1987;41:447-62.

42. Dewey KG , Heinig MJ, Nommsen LA. Maternal weight loss patterns during prolonged lactation. Am J Clin Nutr. 1993; 58:162-6.

43. Gigante D, Victora CG, Barros FC. Breastfeeding has a limited long-time effect on anthropometry and body composition of Brazilian mothers. J Nutr. 2001;131:78-84.

44. Motil KJ, Shen HP, Kertz BL, Montandon CM, Ellis KJ. Lean body mass of well-nourished women is preserved during lactation. Am J Clin Nutr. 1998;67:292-300.

45. Lovelady CA, Garner KE, Moreno KL, Williams JP. The effect of weight loss in overweight, lactating women on the growth of their infants. N Engl J Med. 2000;342:449-53.

46. Chua S, Arulkumaran S, Lim I, Selamat N, Ratnam S. Influence of breastfeeding and nipple stimulation postpartum uterine activity. Br J Obstet Gynaecol. 1994;101:804-5.

\footnotetext{
Corresponding author:

Marina Ferreira Rea

SES - São Paulo

Rua Santo Antônio, 590

CEP 01314-000 - São Paulo, SP

Brazil

Phone: +55 (11) 3293.2254

Fax: +55 (11) 3106.7328
}

Instituto de Saúde, Coordenação dos Institutos de Pesquisa (CIP), 